Discourse and Communication for Sustainable Education, vol. 9, no. 1, pp. 5-17, 2018

\title{
Establishing a Community of Discourse Through Social Norms
}

\author{
Sara Brooke Mullins \\ Virginia Polytechnic Institute and State University, United States of America
}

\begin{abstract}
While researchers, educators, state and national organizations, and policy makers are taking strides to help transform traditional mathematics classrooms into inquiry-based classrooms, they fail to address how to bridge the gap between creating discussions to developing mathematical discourse. One key component for producing inquiry-based classrooms is to have effective discussions (Smith \& Stein, 2011). However, to have effective discussions, social norms must be in place that promote active participation from students (Sherin, 2002). Therefore, the purpose of this paper is to synthesize educational research on social norms in the mathematics classroom to identify key components teacher educators can focus on to help teachers establish and implement social norms that promote sustainable inquiry-based classrooms. Results suggest social norms must be developed through collaboration of the teacher and students, the classroom environment must be supportive of mathematical discussion, and finally, norms should be (re)negotiated to help change students' ways of thinking.
\end{abstract}

Keywords: norms, social norms, sociomathematical norms, mathematics education, discourse, sustainability, inquiry.

\section{Introduction}

For more than a decade, researchers, educators, state and national organizations, as well as policy makers, have pushed for the transformation from traditional lecturebased classrooms to more inquiry-based classrooms. In 2000, the National Council of Teachers of Mathematics (NCTM) set forth their Principles and Standards for School Mathematics (PSSM) to provide guidelines for teachers to support students in learning important mathematical concepts. In doing so, they called for new curriculum and initiated a greater focus on inquiry-oriented instruction. Ultimately, their goal was to move teachers away from lecture towards incorporating mathematical discussions in lessons (NCTM, 2000).

To help teachers implement effective discussions, Smith and Stein (2011) published Five Practices for Orchestrating Productive Mathematics Discussions that gave teachers five specific steps to follow. The goal for them was to help teachers address the issue of 
incorporating mathematical discussions in the classroom "by helping students to learn how to communicate their ideas, making students' thinking public so it can be guided in mathematically sound directions, and encouraging students to evaluate their own and each other's mathematical ideas" (p. 1). Through these discussions, students can think differently about the mathematics, rather than the teacher telling them how to think.

It is not enough to have a discussion in the classroom every now and then; the goal should be to create a sustainable community of discourse (Sherin, 2002). However, Sherin notes"creating and maintaining these environments is a complex endeavor for teachers" (p. 205). According to Dobber, Zwart, Tanis, and van Oers (2017), "The implementation of inquiry-based education in everyday classrooms, however, remains a problematic issue" (p. 3). It is often difficult for teachers to encourage students to engage in conversations concerning mathematics due to the complex nature of the subject (Bennett, 2013). Also, some teachers believe teacher-led discussions count as discourse (Bennet, 2013). Yet, this is not the case; students must be involved in conversations that involve debate, arguments, and justifications for their mathematical ideas to establish "meaningful discourse" (Bennett, 2013, p. 476). Mathematical discourse is not a naturally occurring phenomena, but is something worthwhile to develop.

Ultimately, developing discussions is a step towards creating more sustainable mathematical discourse for inquiry-based classrooms, based on sustainability pedagogical approaches. However, Dobber et al. (2017) note "most research on learning by problemsolving focuses on analyzing the quality of learning outcomes, rather than the circumstances that may promote effective inquiry-based education" (p. 3). As such, NCTM (2000), as well as some other researchers, fail to address a crucial piece for bridging the gap between discussions and discourse; that piece being social norms. Sherin (2002) explains that norms are a key component for creating a community of discourse. Without norms, students do not understand how to participate in discussions (Sherin, 2002). Therefore, the first step to transforming traditional classrooms into inquirybased classrooms is developing social norms.

Social norms refer to the general rules and expectations concerning each person's role in the classroom (Cobb \& Yackel, 1996). In traditional classrooms, students rely on the teacher's responses "rather than to articulate their own understandings" (p. 178). Classroom discussions are often dominated by the teacher and students are only required to offer short responses (Brooks \& Brooks, 1993). However, Smith and Stein (2011) note: "Research tells us that students learn when they are encouraged to become the authors of their own ideas and when they are held accountable for the reasoning about and understanding key ideas" (Engle \& Conant, 2002, p. 2).

However, little research has been conducted on social norms related to developing inquiry-based classrooms. In their study, Dobber et al. (2017) analyzed 186 related to inquiry-based learning and teaching strategies. Interestingly, none of these articles referenced social norms, which is crucial for establishing inquiry in the classroom (Sherin, 2002). Instead, they focused on "social regulation" that "centres on cooperative principles and has to do with guiding the social processes of problem-solving” (p. 11). This addresses issues such as grouping of students but fails to address the issue of social norms in the classroom.

Therefore, the purpose of this paper is to investigate appropriate methods for establishing and implementing social norms to help the sustainability of discourse in a 
mathematics classroom. The hope is to provide teacher educators with new insights on preparing teachers to create sustainable communities of discourse in their classrooms. As such, a discussion of mathematics educational research will be provided. Then, literature on social norms in mathematics education will be synthesized. Following will be a discussion of the articles and implications for teacher educators.

\section{The Context of Mathematics Education Research}

Mathematical learning is often viewed from a constructivist approach where knowledge is constructed by the learner and not passed from person to person (Quale, 2012). Within the constructivist view of learning, researchers focus on the development of deep understanding versus training children to imitate actions (Brooks \& Brooks, 1993). Therefore, in order to develop deep understanding, students must actively construct knowledge based on their experiences (Quale, 2012). Learning should not be viewed as a bank depository in which the teacher inserts knowledge in the students' minds, but rather as the process of using new information to prompt the "emergence or enhancement of cognitive structures" (Brooks \& Brooks, 1993, p. 15) that allows students to rethink prior ideas. Research has shown that when students are active participants in a mathematics classroom, they have more positive attitudes and higher achievement (Aydin, 2016; Garfield, \& Ben-Zvi, 2007; Korsun, 2017; Wora, Hadisaputro, Rohman, Bugis, \& Pambudi, 2017).

Active learning and mathematical discourse are major components for designing mathematics classrooms. As previously mentioned, NCTM's publication of PSSM (2000) advocates for classrooms to become places where students not only learn mathematical processes, but also learn how to think and talk mathematically, through the promotion of mathematical discourse. The goal is for teachers to move away from modeling algorithms students are expected to regurgitate on assignments and move towards providing challenging problems students investigate to develop a solution on their own (NCTM, 2000), essentially creating inquiry-based classrooms.

Within these inquiry-based classrooms, educators have a duty to develop students into mathematical thinkers and doers (NCTM, 2000) by focusing on student understanding. Thus, students need opportunities to engage with high-level tasks so they can learn what it means to do math (Henningsen \& Stein, 1997) and develop essential skills for what it means to know math (Lampert, 1990). In a traditional classroom, doing math is described by students following "rules laid down by the teacher" and knowing math is exemplified by students remembering and applying "the correct rule when the teacher asks a question" (p. 32). However, in inquiry-based classrooms, when students know how to do math, they engage in mathematical tasks and apply their knowledge and understanding of the material to solve the problems (Henningsen \& Stein, 1997). Knowing math indicates that students can argue, defend, challenge, and prove their own ideas (Lampert, 1990). In these situations, students' progress beyond memorization and application of rules and procedures. 


\section{Social and Sociomathematical Norms}

One way to transform traditional classrooms into inquiry-based classrooms is by the establishment or negotiation of social and sociomathematical norms (Cobb, Wood, \& Yackel, 1991). Social norms in a mathematics classroom are defined as a person's "beliefs about [his/her] own role, others' roles, and the general nature of mathematical activity in school" (Cobb \& Yackel, 1996, p. 177). These are general expectations or rules teachers and students have within a classroom. For example, a social norm could be an expectation that students sit quietly and listen to the teacher lecture. This is focusing on students' roles, the teacher's role, and the general activity of lecturing within the classroom. More specific to the mathematics content, sociomathematical norms are defined as "mathematical beliefs and values" (Cobb \& Yackel, 1996, p. 177). These are different from the general classroom activity and are more specific expectations and rules for mathematical behaviors and content (Cobb \& Yackel, 1996). An example of a sociomathematical norm could be that students must justify answers based on mathematical properties (Partanen \& Kaasila, 2015). It is important to understand the distinction between these two, as the establishment of general social norms can either promote or prevent the establishment of sociomathematical norms.

In traditional mathematics classrooms, social norms exist that define the teacher as the authority, and students as perceivers of that knowledge (Cobb et al., 1991). With these norms, students are expected to listen to lectures about methods and strategies they should memorize and then regurgitate on assignments. Students are also expected to be quiet, talking only when the teacher asks a question, and work alone to demonstrate their own competence. These existing social norms force students to answer questions from memorization, rather than having mathematical discussions to explore difference ideas. This example of a non-active environment is not how mathematics classrooms should appear today, as argued by Smith and Stein (2011):

It is unrealistic to expect students to learn to grapple with the unstructured, messy challenges of today's world if they are forced to sit silently in rows, complete basic skills worksheets, and engage in teacher-led "discussions" that consists of literal, fact-based questions and answers. (p. 1)

Instead, students should be active participants in classroom discussions (NCTM, 2000). Students should be focused on developing mathematical skills so they can develop their own knowledge. For this to happen, social norms should be negotiated.

\section{Theoretical Framework}

When looking at the negotiation of social norms as an effective way to establish discursive classrooms, one should consider Cobb and Yackel's (1996) work concerning social norms. Within their framework, Cobb and Yackel state social norms "characterize regularities in communal or collective classroom activity and are jointly established by the teacher and student as members of the classroom community" (p. 178). This implies social norms cannot be created by a single person such as the teacher; they must be mutually constructed between the teacher and students (Cobb et al., 1991). It is also important to note that social norms do not take precedence over students' individual beliefs or vice versa, but rather develop as students change their beliefs (Cobb \& Yackel, 
1996). However, some teachers may impose their own beliefs on students, forcing students to conform to their classroom. As a result, teachers prevent the evolution of new norms, limiting the reorganization of students' beliefs (Cobb \& Yackel, 1996), leading to conflict within the classroom, and resulting in a non-active learning environment.

Three different perspectives to view social norms are used within their framework: the psychological constructivist, the sociocultural, and finally the emergent perspective (Cobb \& Yackel, 1996). The constructivist approach analyses the psychological component concerning social norms in the classroom at an individual level. The goal is to reveal “qualitative difference in individual children's mathematical practices" (p. 180). On the other hand, the sociocultural perspective analyzes the social component from a classroom level. The goal is to gain insight to "what is jointly established as the teacher and students coordinate their individual activities" (p. 180). However, students and teachers do not exist independently of one another, neither do they exist solely dependent on one another. Due to this influence of both psychological and social factors, Cobb and Yackel (1996) combined these two perspectives to create an "interpretive framework" (p. 176) in which they call the emergent perspective.

Through this emergent perspective, researchers look at the development of social norms from two different views: the social and psychological perspectives (Cobb \& Yackel, 1996). By looking at the social component, researchers can see how the teacher and students interact with each other in the classroom and look at norms from a whole class perspective. This interaction provides insight to how knowledge is constructed in the classroom. Then, by looking at the psychological component, researchers can understand each individual person's role within a classroom and how this relates to the norms. Each person in the classroom plays a unique part in the construction of knowledge. For example, if the social norm indicates the teacher is the mathematical authority and the student is the depository, students will rely on the teacher for knowledge; thus, preventing them from individually constructing knowledge. However, if the social norm implies all persons in the classroom are co-constructors of knowledge, then everybody will have an opportunity to engage and construct his or her own knowledge. Within the emergent perspective, "the development of individuals' reasoning and sense-making processes cannot be separated from their participation in the interactive constitution of taken-asshared mathematical meaning" (Yackel \& Cobb, 1996, p. 460). Therefore, when investigating social norms, it is necessary for one to consider both the social and psychological influences that effect the establishment or negotiation of the social norms within the classroom.

More specifically to mathematics education, Yackel and Cobb (1996) suggest that sociomathematical norms are also of importance. Whereas social norms are relative to any classroom, sociomathematical norms go beyond any classroom and are specific to the mathematics classroom. These norms focus on "normative aspects of mathematics discussions specific to students' mathematical activity” (Yackel \& Cobb, 1996, p. 461), such as what counts for an acceptable mathematical solution (Cobb \& Yackel, 1996). Although different in nature, sociomathematical norms can shed light on what social norms might need to be in place to achieve the desired sociomathematical norms. 


\section{Methods}

To investigate appropriate ways for establishing and implementing social norms, the author conducted a search to gain insight to social norms in the mathematics classroom. The author wanted to focus only on middle or high school level classrooms where mathematical discourse is crucial for student learning. Furthermore, empirical studies in peer reviewed journals were targeted to gain a better insight to what is being done in research. Thus, I searched four databases including: ERIC, Educational Research Complete, Psychology and Behavior Sciences Collection, and Teacher Reference Center. I used the following Boolean search terms: social norms OR socio* norms OR class* norms AND math* AND education AND secondary OR middle school OR high school NOT higher education OR college OR university. I included empirical studies conducted globally in middle or high school mathematics classrooms or within mathematics content areas. I also included articles published from 2000 to 2016, with 2000 being the publication year of PSSM and 2016 being the year this study was conducted. I excluded studies conducted at the elementary and post-secondary level, since they are irrelevant to my focus.

Based on this search criterion, 13 articles were produced, indicating the lack of research concerning social norms in mathematics classrooms. From these initial 13 articles, I excluded two non-empirical articles and one article focused on chemistry. This final procedure yielded 10 articles. A review revealed that the 10 articles met the inclusion and exclusion criteria. These articles became my foundation for my review. Data analysis consisted of reading annotating, and synthesizing each article, while looking for emergent themes, which will be discussed in the results section.

\section{Results}

This analysis produced several themes including the following: the classroom environment, the importance of (re)negotiation, and the implementation process. These themes, when considered together, shed light onto social norms in the mathematics classroom and provides teacher educators with new insights on preparing teachers to create sustainable communities of discourse in their classrooms. In the following paragraphs, I will look at these themes in greater detail.

\section{The Classroom Environment}

While parsing the literature, one key component for developing social norms for sustainable communities of discourse that appeared is to ensure the classroom is one in which students feel open to discussions. For example, Weber, Radu, Mueller, Powell and Maher (2010) created an after-school program for sixth graders, with the intention of developing social norms that promote mathematically autonomous students by providing a unique opportunity for students to participate in mathematical activities. A total of five norms were created: (a) students were not told if their answer was right or wrong, (b) students justified answers, (c) students showed work, (d) students discussed and came to a consensus, and (e) students' contributions had to set the stage for other investigations (Weber, et al., 2010). Since the researchers made students feel comfortable and free to discuss answers without embarrassment or degradation, students' particip- 
ation rates increased. The researchers believe that by increasing participation, students were provided with optimal "opportunities to advance their mathematical understanding" (p. 108).

Additionally, the literature highlighted that it is essential to ensure students interpret social norms similarly so that everyone has a clear understanding of the norms. For example, Planas and Civil (2002), looked at how students interpreted social norms differently, what "valorisations", assigning of value or privilege, the teacher used to "establish what counts as valid math... and which participants are well-considered" (p. 179), and how both factors impacted student participation. Results show the teacher created differences between groups of students based on the student's "social positioning" (p. 186), such as treating low socioeconomic status immigrant students different than local students. In addition, the teacher used rude and aggressive behaviors, supporting his actions by stating it was "inevitable and due to the 'bad social habits' of these students" (p.175). As a result, students interpreted the negative valorisations as normal, and interpreted norms differently by placing different meanings on them. Student participation also decreased for the group of immigrant students.

To reemphasize the importance of interpreting and understanding social norms, similarly, Planas and Gorgorio (2004) focused on the production and negotiation of norms, values, and valorisations, "cultural understandings concerning the value (or lack of value) of a social practice (Abreu \& Cline, 2003)" (p. 24), in a multi-ethnic class to determine how students develop an identity as a mathematical learner. Through their analysis, results show the teacher had different expectations for all students (Planas \& Gorgorio, 2004). For instance, the teacher established norms in which local students were not allowed to ask for help and must relate their work to the academic setting. However, immigrant students were expected to listen to local students' explanations, ask questions, and relate their work to real-world situations. Since immigrant students were identified "as less able than other students" (p. 36), they were less willing to participate in classroom discussions. Overall, the teacher's discursive practices had a negative effect on some students preventing them from developing a mathematical learner identity.

Research also shows that by promoting social norms for a competitive learning environment versus a cooperative one can be damaging to student learning. Bratti, Checchi, and Filippin (2011) conducted a study on the "correlation between students' attitudes, in particular cooperative and competitive, and achievement" (p. 276) by looking at data from the Programme for International Student Assessment. From their analysis, results show that individual and peer norms play a part in student learning. Students tend to perform better when they have individual competitive norms. However, when looking at peer norms, "learning in a competitive environment is detrimental to average knowledge, while a cooperative environment favors average performance” (p. 287).

\section{The Importance of (re)Negotiation}

The literature also advises that the negotiation of norms is necessary. González and DeJarnette (2015) conducted a study in six geometry classes to identify the negotiation that occurs in teacher-students' interactions, and who has the "greater responsibility in negotiation exchanges" (p. 2). Results show that each teacher used different negotiation moves and varied in the number of moves used. For example, a total of 382 negotiation 
exchanges occurred between teacher and students, where 97 were from Teacher 1 and 285 were from Teacher 2 . Teachers were also found to have the greatest responsibility in negotiations and were identified as the primary knowers.

Research also suggests that the negotiation of sociomathematical norms is based on previously developed social norms. In their study, Partanen and Kaasila (2015) identified sociomathematical norms that were produced or negotiated during an upper secondary calculus class. During two group discussions, the teacher encouraged students to reexamine a problem and describe what was happening in the problem in their own words. Additionally, the teacher encouraged students to use calculators to explore different representations. All justifications provided by the teacher were based on properties of mathematical objects. As a result, the following three socio-mathematical norms were negotiated: (a) use creative approaches, (b) use different methods, and (c) base justifications on the mathematical properties (Partanen \& Kaasila, 2015). However, the researchers noted that some existing social norms prevented all students from applying the last socio-mathematical norm.

Another key component to developing social norms is to realize it is sometimes obligatory to renegotiate norms to further advance student knowledge. Sometimes students might not fully understand the norms that have been negotiated within a classroom, necessitating a renegotiation of norms. Students might also have pre-existing norms that prevent them from learning and need to be renegotiated. For example, by using two computer-based tools and investigative activities based on big ideas from Statistics, McClain and Cobb (2001) allowed students to explore what it means to make an acceptable argument, in addition to the importance of justifying answers and data creation. As a result, students realized they needed to clarify the data creation process in order to make valid arguments, ultimately renegotiating the idea of an acceptable argument. McClain and Cobb (2001) stated that the produced socio-mathematical norm was "justifying the appropriateness of the ways of structuring and organizing data with respect to the question under investigation" (p. 124). However, before this sociomathematical norm could come to light, the social norm "explain and justify solutions in the context of the problem being explored" (p. 126) had to be negotiated.

\section{The Implementation Process}

From the literature, little research provides insight on the implementation of social and sociomathematical norms. In their study, Clark, Moore, and Carlson (2008) investigated how social and sociomathematical norms emerge during participation in a professional learning community (PLC). In the PLC, teachers learned how to "speak with meaning" (p. 297) by discussing how the material they were learning in class related to their own classroom content. At first, teachers' explanations were simply procedural, but began to provide justifications as the semester progressed. Finally, teachers began to hold each other accountable for their responses and developed criteria for speaking with meaning. As a result, three different signs of speaking with meaning were observed: “1) Absence of speaking with meaning, 2) Participants should speak with meaning (social norm), and 3) Speaking with meaning (sociomathematical norm)" (p. 303). By working in this specific PLC, teachers became successful at understanding norms.

Another example of the implementation process is presented by Putri, Dolk, and Zulkardi's (2015) study of the impact of a professional development (PD) designed to 
help teachers implement social norms in the classroom. Specifically, the researchers studied Pendidikan Matematika Realistik Indonesia (PMRI), an Indonesian educational reform resource which helps teachers learn how to use culturally and locally relevant student-centered activities. Results show that by working in the PD: (a) teachers fulfilled all social norms activities, (b) they recognized they had used social norms, and (c) they gained confidence to use social norms in their mathematics classrooms (Putri et al., 2015). As a result, teachers successfully learned how to establish social norms in the classroom by following a model from the reform resource and information from the PD.

In another study, Depaepe, De Corte, and Verschaffel (2007) investigated teachers' implementation of social norms with the use of the textbook Eurobasis, a Flemish reformbased textbook designed for implementing inquiry-based instruction. The researchers looked at the social dimension of the classroom including: (a) the classroom norms, (b) the instructional techniques, and (c) the set of tasks (Depaepe et al., 2007). Results show that teachers addressed norms relating to "heuristic and metacognitive skills" more than "nature of problem-solving activities" (p. 270), used "powerful instructional techniques like non-direct coaching, articulation, and reflection” (p. 277), rarely used group work, and utilized realistic tasks more than complex ones. Although the textbook was designed to help teachers implement inquiry-based instruction, results show the textbook was not effective in doing so.

\section{Discussion and Conclusions}

From the limited amount of literature, three themes emerged: the classroom environment, the importance of (re)negotiation, and the implementation process. These themes provide a foundation that teacher educators can build on to design programs to help teachers establish and implement social norms that promote sustainable inquiry-based classrooms. In relation to the classroom environment, the classroom needs to become a community in which each person contributes and has value (Weber et al., 2010). Students should not experience social exclusion, as this will limit engagement and participation (Gedžūne, 2015). Students should feel comfortable and open to discuss ideas, without feeling embarrassed, degraded, or humiliated (Weber et al., 2010). The use of negative or aggressive behaviors should not be endorsed, students should be equally positioned in the classroom to promote classroom participation, and students should interpret and place the same meaning on norms (Planas \& Civil, 2002). Furthermore, teachers should develop cultural dispositions to reflect cultural norms and to make connections with students to more effectively address the needs of students and impact student learning (Williams, Edwards, Kuhel, \& Lim, 2016). Teachers should be obligated to set the same model and expectations for students, allowing students to develop identities as mathematical learners (Planas \& Gorgorio, 2004). Therefore, cooperative social norms should be encouraged while competitive ones are avoided to allow students to have higher performance (Bratti et al., 2011). As teacher educators, it is important to help teachers understand the importance of developing social norms that promote a positive classroom environment, conducive to learning and participation. By reflecting on previous research, teacher educators can address these highlighted issues that prevent teachers and students from having appropriate social norms that enable productive discourse. Teacher educators should work with teachers to help them investigate acceptable social norms that promote communities of discourse. 
Moreover, it is essential to (re)negotiate norms to help change students' ways of thinking (González \& DeJarnette, 2015; McClain \& Cobb, 2001). Social norms should be focused on interactions and conversations that can help students become the primary knower (González \& DeJarnette, 2015), and no longer rely on teacher knowledge (Cobb \& Yackel, 1996). However, teachers often take for granted that what they expect students to know and do is common knowledge, but students might already have social norms developed from another class that contradict the teacher's expectations (McClain \& Cobb, 2001). Therefore, it is important to identify social norms that might prevent students from reaching the sociomathematical norm (Partanen \& Kaasila, 2015), and then renegotiate those social norms to help establish sociomathematical norms. Teacher educators should help teachers learn how to work in conjunction with students to negotiate social norms. Additionally, teacher educators should help teachers learn how to reflect on previous norms to understand ways to approach new social norms in their classrooms. By taking a collaborative and reflective approach, teacher educators can help teachers understand ways in which social norms can be established to help foster the development of an inquiry-based classroom.

To highlight the need for helping teachers understand how to implement norms, Świtala (2010) found that about $40 \%$ of teachers in one Polish school and about $14 \%$ in another Polish school could not explain how they fostered values, or norms, in their classrooms. Out of those teachers in the first school who could identify techniques, one teacher selected "discussion of values with students" and one teacher selected "allowing students to have their own opinions", while most teachers selected "showing own example" as the most prominent way to foster values (p. 60). In the second school, similar results appeared with only one teacher selecting "allowing students to have their own opinions" and the majority again selecting "showing own example" as the most prominent way to foster values (p. 61). This suggests there is a desperate need for teacher educators to assist teachers understand how to establish and implement social norms in the classroom.

One difficulty, however, teacher educators might face when helping teachers establish social norms is the teacher's control of power. In the early 1990's teachers were reluctant to loosen control of the classroom (Brooks \& Brooks, 1993), and arguably, this has most likely heightened in age of high accountability and standardized testing. This power struggle now between learning outcomes and standardization could cause some to return to a more traditional approach to teaching and learning (Brooks \& Brooks, 1993; Vetter, Meacham, \& Schieble, 2013). Some teachers also have an internal power struggle as they fight against who they want to be and who they are in the classroom (Vetter et al., 2013). For example, when teachers encounter resistance from students, they often return to traditional power controlling roles instead of negotiating shared power with students (Vetter et al., 2013). Based on this evidence, teachers need more help learning how to (re)negotiate norms in the classroom. Teacher educators should help teachers understand how to collaborate with students to establish social norms, while also realizing there is an appropriate amount of power the students need to have in the classroom to create a community of discourse. Teacher educators should emphasize the students' needs for control while helping teachers maintain their own control in the classroom through the negotiation of social norms.

Finally, the literature highlights the need for teacher support that focuses on knowledge of social norms, beneficial resources, and effective implementation strategies. By 
working with a PD program, a PLC, and inquiry-based materials, teachers can learn how to negotiate social norms in the classroom (Clark et al., 2008; Depaepe et al., 2007; Putri et al., 2015). However, simply proving teachers with these opportunities and resources is not enough. A PLC and PD program is only effective for helping teachers implement social norms in their classroom if this topic is directly addressed in the PLC and teachers are given opportunities to practice establishing and negotiating social norms in their classrooms. Furthermore, materials such as textbooks are not an automatic fix (Depaepe et al., 2007), but must be supported with other resources. Therefore, teacher educators should spend an extensive amount of time working with teachers to practice implementing social norms in classrooms. Teacher educators should focus on supplementing available resources (e.g., PD, PLC, and textbooks) to help teachers understand how to properly implement social norms.

What this research suggests is that social norms must be developed through collaboration of the teacher and students, the classroom environment must be supportive of mathematical discussion, and finally, norms should be should (re)negotiate norms to help change students' ways of thinking. By using these key components, teacher educators can help teachers create sustainable communities of discourse and inquiry-based classrooms where students actively construct their own knowledge, ultimately establishing "an environment which would stimulate students' creative and cognitive interaction with the world" (Briede, 2016, p. 45). Teacher educators should allow teachers opportunities to practice implementing social norms, permitting teachers to become more confident in their practices of creating communities of discourse. Teacher educators should also follow teachers in their classrooms to see if the implementation of social norms was effective, providing data to reflect on and improve their teacher education programs. By looking at such areas, teacher educators could propel mathematics education forward in terms of making classrooms more inquiry-based. If teacher educators can help teachers learn about social norms, appropriate methods of negotiation, and proper implementation strategies, new strides can be made towards meeting NCTM's (2000) goals for transforming mathematics classrooms into more inquiry-oriented classrooms. By focusing on these three areas, teacher educators can help teachers foster deep learning, meet NCTM's (2000) goals, and develop more sustainable communities of discourse and inquiry-based classrooms.

\section{References}

Abreu, G., \& Cline, T. (2003). Schooled mathematics and cultural knowledge. Pedagogy, Culture and Society, 11(1), 11-30.

Aydin, S. (2016). Using Excel in teacher education for sustainability. Journal of Teacher Education for Sustainability, 18(20), 89-104. doi: 10.1515/jtes-2016-0017.

Bennett, C. A. (2013). Teachers' perspectives of whole-class discourse: Focusing on effective instruction to improve student learning. Action in Teacher Education, 35(5-6), 475-488. doi: 10.1080/01626620.2013.846765.

Bratti, M., Checchi, D., \& Filippin, A. (2011). Should you compete or cooperate with your schoolmates? Education Economics, 19(3), 275-289. doi: 10.1080/09645292. 2011.585021. 
Briede, L. (2016). The relationship between mathematics teachers' teaching approaches and 9th grade students' mathematical self. Journal of Teacher Education for Sustainability, 18(1), 34-47. doi: 10.1515/jtes-2016-0003.

Brooks, J., \& Brooks, M. (1993). The case for constructivist classrooms. Alexandria, VA: ASCD.

Clark, P. G., Moore, K. C., \& Carlson, M. P. (2008). Documenting the emergence of "speaking with meaning" as a sociomathematical norm in professional learning community discourse. Journal of Mathematical Behavior, 27(4), 297-310.

Cobb, P., \& Yackel, E. (1996). Constructivist, emergent, and sociocultural perspectives in the context of developmental research. Educational Psychologist, 31(3-4),175190. doi: 10.1080/00461520.1996.9653265.

Cobb, P., Wood, T., \& Yackel, E. (1991). Analogies from the philosophy and sociology of science for understanding classroom life. Science education, 75(1), 23-44. doi: 10.1002/sce.3730750104.

Depaepe, F., De Corte, E., \& Verschaffel, L. (2007). Unraveling the culture of the mathematics classroom: A video-based study in sixth grade. International Journal of Educational Research, 46(5), 266-279. doi: 10.1016/j.ijer.2007.10.008.

Dobber, M., Zwart, R., Tanis, M., \& van Oers, B. (2017). Literature review: The role of the teacher in inquiry-based education, Educational Research Review, doi: 10.1016/ j.edurev.2017.09.002.

Engle, R. A., \& Conant, F. C. (2002). Guiding principles for fostering productive disciplinary engagement: Explaining an emergent argument in a community of learners' classroom. Cognition and Instruction, 20(4), 399-483. doi: 10.1207/S1532690X CI2004_1.

Garfield, J., \& Ben-Zvi, D. (2007). How students learn statistics revisited: A current review of research on teaching and learning statistics. International Statistical Review, 75(3), 372-396. doi: 10.1111/j.1751-5823.2007.00029.x.

Gedžūne, G. (2015). Awakening pre-service teachers to children's social exclusion in the classroom. Discourse and Communication for Sustainable Education, 6(1), 95-109. doi: 10.1515/dcse-2015-0007.

González, G., \& DeJarnette, A. F. (2015). Teachers' and students' negotiation moves when teachers scaffold group work. Cognition and Instruction, 33(1), 1-45. doi: 10.1080/07370008.2014.987058.

Henningsen, M., \& Stein, M. K. (1997). Mathematical tasks and student cognition: Classroom-based factors that support and inhibit high-level mathematical thinking and reasoning. Journal for Research in Mathematics Education, 28(5), 524-549.

Korsun, I. (2017). The formation of learners' motivation to study physics in terms of sustainable development of education in Ukraine. Journal of Teacher Education for Sustainability, 19(1), 117-128. doi: 10.1515/jtes-2017-0008.

Lampert, M. (1990). When the problem is not the question and the solution is not the answer: Mathematical knowing and teaching. American Educational Research Journal, 27(1), 29-63. doi: 10.2307/1163068.

McClain, K., \& Cobb, P. (2001). Supporting students' ability to reason about data. Educational Studies in Mathematics, 45(1/3), 103-129. doi: 10.1023/A:10138745 14650.

National Council of Teachers of Mathematics. (2000). Principles and standards for school mathematics. Reston, VA: The National Council of Teachers of Mathematics, Inc. 
Partanen, A., \& Kaasila, R. (2015). Sociomathematical norms negotiated in the discussions of two small groups investigating calculus. International Journal of Science and Mathematics Education, 13(4), 927-946. doi: 10.1007/s10763-014-9521-5.

Planas, N., \& Civil, M. (2002). Understanding interruptions in the mathematics classroom: Implications for equity. Mathematics Education Research Journal, 14(3), 169-189. doi: 10.1007/BF03217361.

Planas, N., \& Gorgorio, N. (2004). Are different students expected to learn norms differently in the mathematics classroom? Mathematics Education Research Journal, 16(1), 19-40. doi: 10.1007/BF03217389.

Putri, R. I., Dolk, M., \& Zulkardi. (2015). Professional development of PMRI teachers for introducing social norms. Indonesian Mathematical Society Journal on Mathematics Education, 6(1), 11-19.

Quale, A. (2012). On the role of constructivism in mathematical epistemology. Constructivist Foundations, 7(2), 104-112.

Sherin, M. G. (2002). A balancing act: Developing a discourse community in a mathematics classroom. Journal of Mathematics Teacher Education, 5(3), 205-233. doi: 10.1023/ A:1020134209073.

Smith, M. S., \& Stein, M. K. (2011). 5 practices for orchestrating productive mathematics discussions. Reston, VA: NCTM.

Świtala, E. (2010). Values across countries in a modern society: The example of polish schools. Discourse and Communication for Sustainable Education, 1(2), 55-63. doi: 10.2478/dcse-2013-0014.

Vetter, A., Meacham, M., \& Schieble, M. (2013). Leveling the field: negotiating positions of power as a preservice teacher. Action in Teacher Education, 35(4), 230-251. doi: 10.1080/01626620.2013.827598.

Weber, K., Radu, I., Mueller, M., Powell, A., \& Maher, C. (2010). Expanding participation in problem solving in a diverse middle school mathematics classroom. Mathematics Education Research Journal, 22(1), 91-118. doi: 10.1007/BF03217560.

Williams, D. L., Edwards, B., Kuhel, K. A., \& Lim, W. (2016). Culturally responsive dispositions in prospective mathematics teachers. Discourse and Communication for Sustainable Education, 7(2), 17-33. doi: 10.1515/dcse-2016-0013.

Wora, V. M., Hadisaputro, R., Rohman, N., Bugis, H., \& Pambudi, S. N. A. (2017). Student improvement by applying the numbered heads together (NHT) approach to basic subjects of vocational competence in a vocational high school in Indonesia. Discourse and Communication for Sustainable Education, 8(2), 94-102. doi: 10.1515/dcse-2017-0018.

Yackel, E., \& Cobb, P. (1996). Sociomathematical norms, argumentation, and autonomy in mathematics. Journal for Research in Mathematics Education, 27(4), 458-477.

Correspondence concerning this paper should be addressed to Brooke Mullins, Virginia Polytechnic Institute and State University, The United States of America. Email: sbm3@vt.edu 